\title{
A rare case of hydatid cyst in the breast in a tertiary care hospital in Bangalore, Karnataka, India
}

\author{
Vikram. H. C. V. ${ }^{\mathbf{1}}$, Manasa S. ${ }^{2 *}$ \\ DOI: https://doi.org/10.17511/ijoso.2020.i04.10
}

1 Venkatesh Vikram. H. C., Medical Director, Department of Microbiology, Sagar Hospitals DSI, Bangalore, Karnataka, India.

2* Manasa S., Junior Infection Control Officer, Department of Microbiology, Sagar Hospitals DSI, Bangalore, Karnataka, India.

\begin{abstract}
Hydatid disease is a well-known entity since the era of Hippocrates. Although breast is one of the rare sites for the occurrence of hydatid disease, it has been well evaluated with the various newer imaging modalities and its imaging features are well described in the literature. A 41-year-old female presented with a painless well-defined lump in the right breast without any history of pain, trauma, discharge from the nipple, fever, or drug misuse. This case was diagnosed preoperatively by FNAC, ultrasound, and was confirmed by surgery. Hydatid disease of the breast should form the part of the differential diagnosis of cystic diseases of the breast especially in an endemic country like India. Awareness of this entity can make the pre-operative diagnosis even without cytological examination, which is very helpful in the management of the patient.
\end{abstract}

Keywords: Hydatid disease, Breast, Hydatid cyst, Painless swelling of breast.

Corresponding Author

Manasa S., Junior Infection Control Officer, Department of Microbiology, Sagar Hospitals DSI, Bangalore, Karnataka, India.

Email: manasabharadwaj86@gmail.com
How to Cite this Article

Venkatesh VHC, Manasa S. A rare case of hydatid cyst in the breast in a tertiary care hospital in Bangalore, Karnataka, India. Surgical Rev Int J Surg Trauma Orthoped. 2020;6(4):282-285.

Available From

https://surgical.medresearch.in/index.php/ijoso/artic le/view/194
To Browse

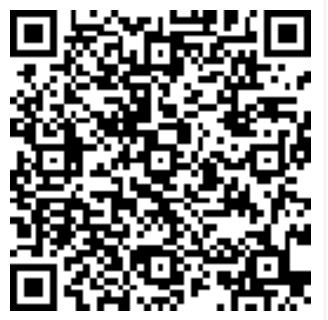

\section{Introduction}

The hydatic disease is a severe, potentially lethal disease caused by Echinococcus granulosus larvae. The infection with $E$. granulosus should be seen as a challenge both from a medical and economic point of view [1].

E. granulosus is a hermaphrodite flatworm with three stages of development. The structure of the cyst is usually made of three components: the pericyst, made of the host's inflammatory tissue, the exocyst and the
Endocyst, where the scolecs and the proligere membrane are produced $[3,4]$. This is encountered endemically in sheep breeding communities. Humans are occasional intermediate hosts of this organism. The oncospheres, which are ingested, penetrate the intestinal mucosa, enter the bloodstream, and develop into hydatid cysts. Hydatid cyst most commonly occurs in the liver (50-70\% of cases), and less commonly in the lungs, spleen, kidneys, and brain [5-7]. The breast is a very rare site of hydatid cyst that accounts for only $0.27 \%$ of all cases [8].
Manuscript Received 2020-07-10

Conflict of Interest No

Review Round 1
2020-07-31
Funding
Nil

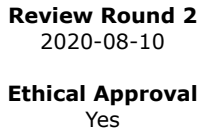

Review Round 2

Yes
Review Round 3

Plagiarism X-checker $8 \%$
Accepted 2020-08-28

(c) 2020 by Venkatesh Vikram. H. C., Manasa S. and Published by Siddharth Health Research and Social Welfare Society. This is an Open Access article licensed under a Creative Commons Attribution 4.0 International License https://creativecommons.org/licenses/by/4.0/ unported [CC BY 4.0]. 


\section{Case Report}

A 41-year-old woman from Raichur district presented with a lump in the right breast without any family history of carcinoma breast.

She had no history of pain, trauma, discharge from the nipple, fever, or drug misuse. There was no abdominal or chest complaint. On clinical examination, there was a well-defined, non-tender mass of $11.0 \times 6.0 \mathrm{~cm}$, with restricted mobility, occupying the lower inner and lower outer quadrants of the right breast.

The left breast was normal. Both nipples were normal and she had no axillary or supraclavicular lymphadenopathy. There was no mass in the abdomen. Fine needle aspiration cytology from lump yielded $10 \mathrm{ml}$ of clear fluid from different sites. The sediment smear showed very sparse cellularity.

There were no ductal epithelial cells or cyst macrophages. The mammogram showed a dense fibro glandular stroma with large well-defined opacity that was noted occupying all quadrants [Fig 1].

Ultrasound showed a thick-walled multiloculated cystic lesion measuring $11 \times 6 \mathrm{cms}$ occupying the lower inner and lower outer quadrants.

All the locules show low-level internal echoes. Few specs of calcification are seen on the wall.

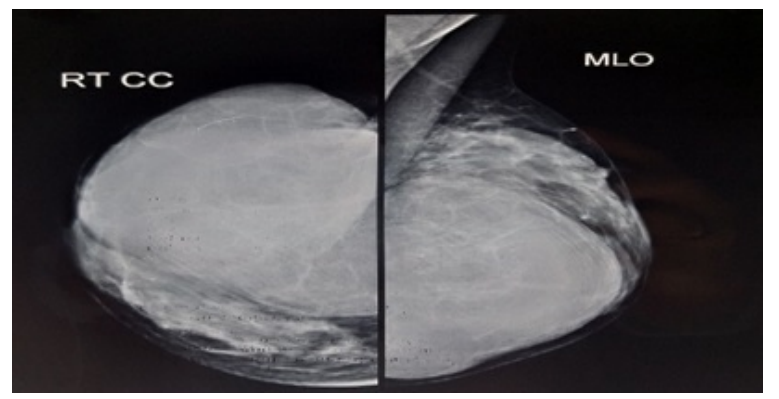

Fig-1: Mammogram showing well defined smooth-walled opacity in the right breast.

The patient underwent surgery for the removal of the right breast lump. Through a curvilinear incision just above the areolar margin, the cyst was removed in-toto. The excised cyst was oval in shape and measured $11 \mathrm{~cm} \times 6 \mathrm{~cm} \times 3 \mathrm{~cm}$.

When the cyst was opened, endocysts were found confirming it to be a hydatid cyst.

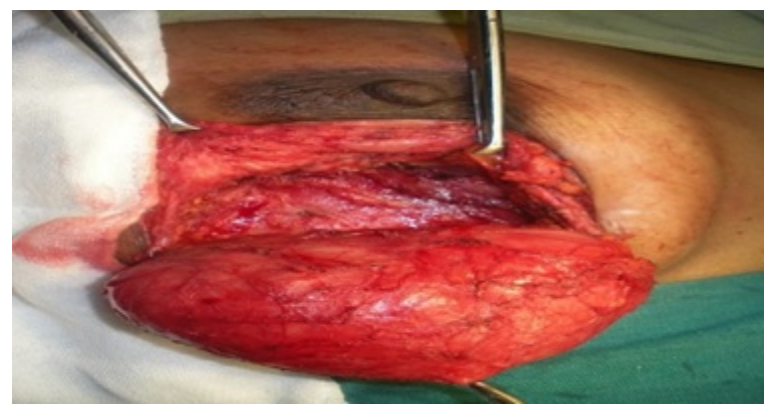

Fig-2: Intraoperative cyst.

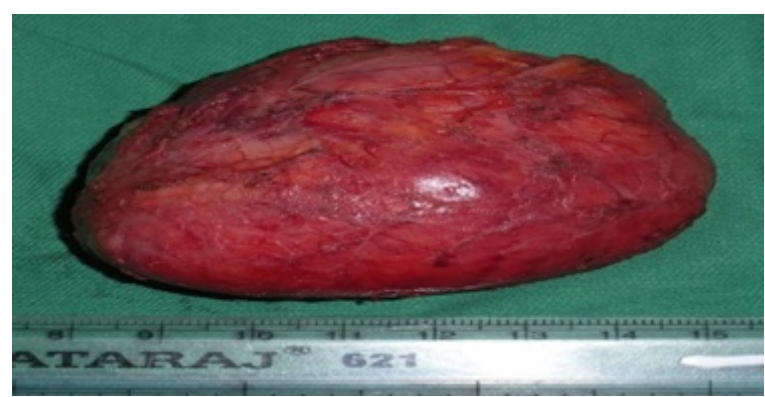

Fig-3: Excised cyst.

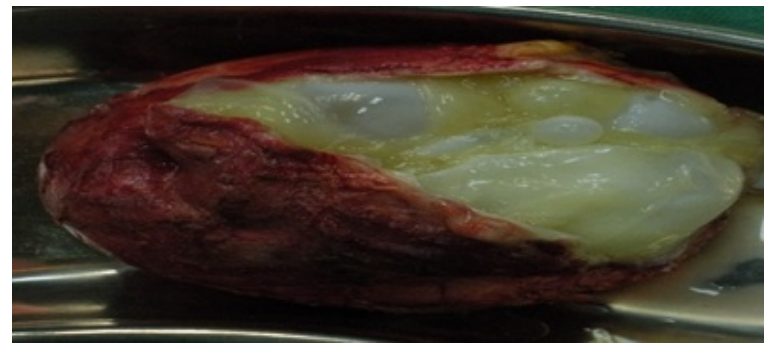

Fig-4: Excised cyst with endo cyst.

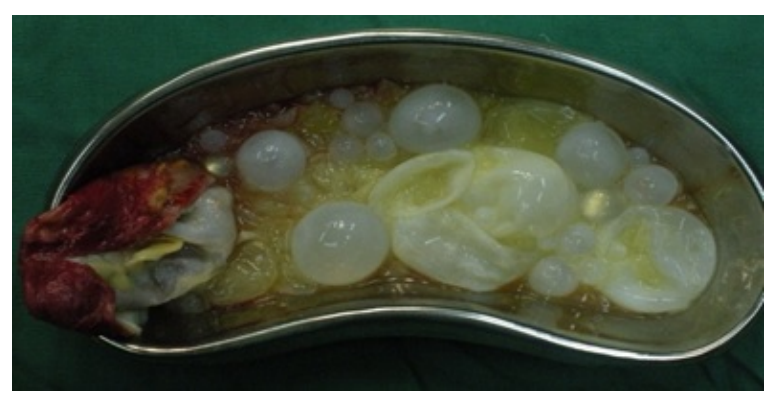

Fig-5: Excised cyst with daughter cysts.

\section{Discussion}

Hydatid disease is caused by a larva of Echinococcus granulosus and rarely Echinococcus multilocularis. The disease is endemic in central India. Due to its varied morphological presentations and involvement of various sites in the body, it gives rise to varying clinical symptomatology. Painless local swelling is the most common presenting complaint in the case 
Of hydatid disease of the breast. Man is usually an accidental host, primary hosts being Dogs, Sheep, etc. Hydatid disease can be found in any age group and anybody sites. The location is mostly in the liver (75\%) and lungs (15\%), with only $10 \%$ occurring in other parts of the body; in the breast, it only accounts for $0.27 \%$ of all cases. Hydatid disease of the breast is extremely rare even in endemic areas; it can be the only primary site or part of disseminated hydatidosis. Histologically hydatids consist of three layers-

01. Endocyst (Parasite component of capsule)- inner germinal layer giving rise to brood capsules.

02. Ectocyst (Cyst membrane) - a substance secreted by a parasite.

03. Pericyst (Host component) - organized host granulation tissue.

Patients usually present with a palpable and painless lump in the breast. Differentiation of lesions from other tumors can be challenging. Only a few reports are published and the majority of the reported cases have been diagnosed postoperatively [8]. In the present case, the breast lump was not painful and has gradually enlarged in size.

The imaging modalities for the diagnosis of breast hydatid disease are mammography, ultrasound, and MRI. Mammography shows a nonspecific, homogeneous, smooth, circumscribed lesion [9]. When secondary infection occurs, a hydatid cyst cannot be distinguished from breast abscess, clinically by mammography [10]. The mammogram showed a dense fibro glandular stroma with large well-defined opacity that was noted occupying all quadrants.

The ultrasound findings vary according to the degree of maturation and complications. Gharbi et al. have described five types of ultrasound findings for hydatid cysts. Types II and III hydatid cysts have more reliable diagnostic imaging properties than other types [11]. Multiple daughter cysts separated by a fluid matrix that contains a mixture of membranes of broken daughter vesicles, scolices, and hydatid sand with mixed echogenicity may give rise to a "wheel-spoke" pattern. Separation of the ruptured endocyst layer from the ectocyst leads to a free-floating membrane that produces the so-called water lily sign [10-12].

In the present case, an ultrasound showed a thickwalled multiloculated cystic lesion measuring $11 \mathrm{x}$ $6 \mathrm{cms}$ occupying the lower inner and lower outer
Quadrants. All the locules show low-level internal echoes. Few specs of calcification are seen on the wall.

The differential diagnosis based on mammography would include cyst, fibroadenoma, phyllodes tumor, and, rarely circumscribed carcinoma. Vega et al. noted that the presence of ring-shaped structures and interseptal bands in the slowly growing breast mass should suggest a hydatid cyst [9]. While morphology is important and criterion for the staging of hydatid disease, imaging modalities having high contrast resolution should be considered in selected cases for investigation. According to the stage of the hydatid disease, MRI also had the capability to show lesion characteristics, and perilesional soft tissue changes better than sonography. MRI findings can be helpful but not specific. The findings of the cystic lesion with capsular enhancement are suggestive of hydatid cyst. The capsular enhancement is more typical with secondary infection. Hydatid cyst can present with no capsular enhancement. Diagnosis is frequently delayed due to no specific signs are found at the time of examination, and they instead mimic other pathologies. A hydatid cyst is usually not included in the differential diagnosis of breast lumps due to its rarity, even in endemic areas.

\section{Conclusion}

Hydatid cyst of the breast is very uncommon. It is very challenging to differentiate it from other tumoral lesions of the breast. However, it should be included in the differential diagnosis of breast lumps for patients living in endemic areas. Fine needle aspiration cytology can help in its preoperative diagnosis, but the majority of the reported cases have been diagnosed postoperatively. Recurrence after surgical removal has been reported but postoperative Albendazole may decrease its recurrence rate.

\section{Reference}

01. Lightowlers MW. Vaccines against cysticercosis and hydatidosis- foundations in taeniid cestode immunology. Parasitol Int. 2006;55;S39-S43.

[Crossref]

02. Pedrosa I, Saíz A, Arrazola J, Ferreirós J, Pedrosa CS. Hydatid disease- radiologic and pathologic features and complications. Radiographics. $2000 ; 20(3) ; 795-817$. [Crossref] 
03. Polat $P$, Kantarci M, Alper F, Suma S, Koruyucu MB, Okur A. Hydatid disease from head to toe. Radiographics. 2003;23(2)475-494.

[Crossref]

04. Moro P, Schantz PM. Echinococcosis - a review. Int J Infect Dis. 2009;13(2)125-133.

[Crossref]

05. Nunnari G, Pinzone MR, Gruttadauria S, Celesia BM, Madeddu G, Malaguarnera G, et al. Hepatic echinococcosis - clinical and therapeutic aspects. World J Gastroenterol. 2012;18(13)1448-1458.

[Crossref]

06. Khanfar N. Hydatid disease- a review and update. Current Anaesthes Crit Care. 2004;15(3)173-183.

[Crossref]

07. Dagli AF, Ozercan MR, Kocakoc E. Hydatid cyst of the breast mimicking inflammatory carcinoma and mastitis. J Ultrasound Med. 2006;25(10)1353-1356.

[Crossref]
08. Gharbi HA, Hassine W, Brauner MW, Dupuch K. Ultrasound examination of the hydatic liver. Radiol. 1981;139(2)459-463.

[Crossref]

09. von Sinner WN. New diagnostic signs in hydatid disease; radiography, ultrasound, CT and MRI correlated to pathology. Europe J Radiol. $1991 ; 12(2) 150-159$.

[Crossref]

10. Garcia-Diez AI, Mendoza LR, Villacampa VM, Cozar M, Fuertes MI. MRI evaluation of soft tissue hydatid disease. Europe Radiol. $2000 ; 10(3) 462-466$.

[Crossref]

11. Abi F, Khaiz D, Bouzidi A. Unusual localizations of hydatid cysts, Apropos of 40 cases. J de chirurgie. 1989;126(5)307-312.

[Crossref]

12. Vega A, Ortega E, Cavada A, Garijo F. Hydatid cyst of the breast- mammographic findings. AJR- Am J Roentgenol. 1994;162(4)825-826. [Crossref] 